\title{
Imagem corporal e sexualidade de adolescentes com cegueira, alunos de uma escola pública especial em Feira de Santana, Bahia
}

\author{
Dalva Nazaré Ornelas França* \\ Eliane Elisa de Souza e Azevedo*
}

\begin{abstract}
Resumo
Seis adolescentes com cegueira congênita, alunos da Fundação Jonathas Telles de Carvalho, em Feira de Santana, concordaram em participar da presente pesquisa respondendo questionários e outros instrumentos de entrevista sobre imagem corporal e sexualidade. Os resultados demonstram que os adolescentes com cegueira têm fiel percepção de sua imagem corporal, que é construída a partir do que lhe dizem e pelo toque do próprio corpo. Em todos os adolescentes foi observado elevado nível de auto-estima e autopercepção como sexualmente atraentes. Existe consciência das transformaçôes corporais da adolescência, embora com desinformação e receio sobre as mesmas. Todavia prevalece o desejo de construir uma relação afetivo-sexual, desejo esse semelhante ao dos adolescentes videntes. A ausência no país de um modelo pedagógico especial para educação sexual de portadores de deficiência visual agrava os desafios desta fase da vida e predispõe a preconceitos por parte da sociedade.
\end{abstract}

Palavras-chave: Imagem corporal. Sexualidade. Cegueira. Adolescente.

\section{INTRODUÇÃO}

$\mathrm{Na}$ adolescência, intensifica-se a consciência da identidade em função das modificações que, de forma radical, ocorrem no corpo e levam os jovens a compararem-se com padrôes estabelecidos em seu meio social (SCHOENFELD, 1968). Os adolescentes, de maneira geral, buscam identificar em outras pessoas, através da visão, um modelo para ajudá-los na reconstrução da própria imagem corporal. A oportunidade de ver outros corpos facilita a idéia de como ficará o seu, após as modificações da puberdade.

Nas pessoas com cegueira, existe a perda do sentido de fundamental importância para a construção da imagem corporal, a qual favorece a construção da identidade. Neste processo, quais os recursos que busca o adolescente com cegueira para auxiliar a construção da auto-imagem corporal?

Tiba (1986), ao se referir à construção do esquema corporal, reconhece que o adolescente enfrenta duas situações básicas: aquela do corpo diante de si mesmo e a do corpo em relação ao dos outros. O esquema corporal é a representação mental do corpo. A cada modificação do corpo, admite-se que também se modifica o esquema corporal. $\mathrm{Na}$ adolescência, porém, as sucessivas alteraçôes corporais, tanto na forma quanto em conteúdo, ocorridas em um tempo

\footnotetext{
*Professora de Educação Sexual. Departamento de Ciências Biológicas. UEFS.

** Professora de Bioética. Departamento de Ciências Biológicas. UEFS.

Núcleo Integrado de Educação Sexual

Departamento de Ciências Biológicas

Universidade Estadual de Feira de Santana

Km 03 BR 116 - Feira de Santana Bahia Brasil

E-mail:sdfranca@gf.com.br
} 
relativamente curto, nem sempre são acompanhadas de modificaçáo do esquema corporal. Assim, as sensaçōes sinestésicas do adolescente e sua aparência física não coincidem, ou mesmo conflitam, com o seu esquema corporal.

Os poucos estudos que enfocam a imagem corporal e a sexualidade do adolescente com cegueira respaldam, teoricamente, o interesse à reflexão sobre o tema, reconhecendo que o adolescente com cegueira passa por conflitos e desejos semelhantes aos do adolescente vidente, todavia inexistem, no Brasil, pesquisas sobre o tema.

Considerando este conjunto de observaçốes, o presente trabalho se propóe a estudar como o adolescente com cegueira constrói sua imagem corporal e como lida com as manifestaçôes da sexualidade nesta fase da vida.

\section{MATERIAL E MÉTODO}

Por tratar-se de amostragem intencional, à qual somente interessavam adolescentes com cegueira congênita e que estivessem freqüentando a escola, buscou-se a Fundação Jonathas Telles de Carvalho, por ser a instituição que oferece um serviço de apoio pedagógico a todos os alunos com cegueira que estão na rede pública de ensino da cidade de Feira de Santana, Bahia. Nesta instituição, foram selecionados todos os adolescentes com cegueira congênita, com idades entre 10 e 19 anos.

Para avaliação da auto-imagem, foram utilizados os seguintes instrumentos: 1) Questionário com questôes voltadas para auto-imagem, modificaçôes corporais e manifestaçẫo da sexualidade. 2) Complementação de frases, com vistas a analisar o sentimento em relação ao corpo e a sua relação como sexualidade. 3) Escala de autovaloração, com o objetivo de mensurar o grau de auto-estima. Os Quadros com os resultados demonstram o conteúdo dos instrumentos.

Anteriormente à coleta de dados, o projeto fora aprovado pelo Comitê de Ética em Pesquisa do Hospital São Rafael, Salvador, Bahia.
Antes da aplicação dos instrumentos da pesquisa, o Termo de Consentimento Livre e Esclarecido (Resolução 196/96, CONEP/CNS/MS), foi apresentado (lido), individualmente, a cada adolescente, tornando-os conhecedores de todos os procedimentos da pesquisa, deixando-os livres para aceitar, recusar ou desistir em qualquer momento dos trabalhos.

\section{RESULTADOS E DISCUSSÃO}

Foram identificados e estudados seis adolescentes com cegueira congênita, sendo três do gênero masculino e três do gênero feminino, com idades de 12,14, 19 e 10,15, 18 anos, respectivamente.

O Quadro 1 demonstra que, ao informarem sobre sua auto-imagem, por consulta seguida de oferta de alternativas, os adolescentes com cegueira demonstraram possuir fiel percepção sobre sua aparência pessoal. As respostas foram compatíveis com o observado pela Pesquisadora, exceto em dois dos adolescentes, que não se revelaram seguros em suas respostas. Um deles achava-se confuso entre o que ele se imaginava e o que sua genitora dizia em relação à sua etnia. Curiosamente, a sua opiniāo era a correta. Um outro auto-identificou-se como sendo negro, quando sua aparência era de mulato.

Elevada auto-estima foi observada em todos os entrevistados, uma vez que, sem exceção, todos afirmaram considerarem-se bonitos e simpáticos. Uma das adolescentes afirmou que, além de considerar-se bonita, reconhecia-se como "maravilhosa". Esta mesma adolescente portouse de forma inquieta durante todo o tempo da entrevista, demonstrando-se preocupada com os cabelos e com sua aparência geral. Interpretouse esta atitude como uma característica de vaidade, presente nos adolescentes em geral.

Os resultados do Quadro 2 demonstram que os adolescentes com cegueira dispensam atenção e preocupação especial ao próprio corpo e às modificaçôes que estão acontecendo ou que já aconteceram. Esta constatação reafirma que os adolescentes com cegueira enfrentam os 


\begin{tabular}{|l|lll|}
\hline Categoria de & \multicolumn{3}{|c|}{$\begin{array}{c}\text { Grupos intracategorias } \\
\text { número observado }\end{array}$} \\
\hline Etnia & Branco & Mulato & Negro \\
& 1 & $4^{*}$ & $1^{* *}$ \\
Estatura & Alto & Médio & Baixo \\
& 2 & 2 & 2 \\
Peso & Gordo & Médio & Magro \\
& 3 & 2 & 1 \\
Aparência etária & Jovem & Meia-idade & Idoso \\
& 5 & 1 & 0 \\
Timbre de voz & Grossa & Média & Fina \\
& 0 & 3 & 3 \\
Aparência estética & Feia & Bonita & Outra*** \\
& 0 & 5 & 1 \\
Carisma & Simpático & Antipático & Outro \\
& 6 & 0 & 0 \\
\hline
\end{tabular}

Quadro 1 - Distribuição dos tipos de auto-imagem em seis adolescentes com cegueira, alunos da Fundação Jonathas Telles de Carvalho, Feira de Santana, Bahia

* Um desses adolescentes referiu-se como "mulato", acrescentando que sua mãe o identifica como "moreno claro".

** Identificou-se como "negro", embora seja "mulato".

*** O termo usado pela adolescente foi: "Maravilhosa".

mesmos conflitos que os demais adolescentes, independentemente da deficiência visual. Observa-se uma certa preocupação com a imagem que os outros constroem sobre eles (3/3), o que é comum à fase da adolescência nos videntes. Novamente, confirma-se o elevado nível de autoestima, quando 5/6 afirmaram que não gostariam de ter aparência diferente da que têm, e todos eles (6/6) sentem-se sexualmente atraentes.

Os adolescentes estudados foram, de alguma forma, informados sobre as mudanças corporais que iriam acontecer, porém de modo não sistemático (QUADRO 3). Todos têm consciência das partes do seu corpo e têm preferências por partes específicas, incluindo os órgãos genitais e os seios, partes estas que mais se evidenciam durante a puberdade. A maioria deles gostaria de mudar pontos específicos de sua aparência física, demonstrando, assim, a vaidade característica desta fase. Nenhum dos adoles- centes pesquisados sugeriu mudar os olhos, o que implica em aceitação de sua realidade.

Estas observações corroboram a afirmação de Vigotsky (1995), de que "a cegueira não se revela uma desgraça enquanto defeito biológico, mas assim se transforma, devido ao meio social onde se estabelece". Em especial para as pessoas com cegueira congênita, não existem parâmetros objetivos de avaliação da intensidade da deficiência. Não fora o contato social com os videntes e/ou os preconceitos deles advindos, a situação limitante seria menos trágica. A aceitação das variabilidades da espécie humana, como variedades inerentes à própria natureza biológica da espécie, sem o discriminante rótulo de "anormalidades" é o fundamental ético para o convívio social sem traumas e moralmente justo.

O toque e a voz são a "visão" dos indivíduos com cegueira. Foram explorados estes dois aspectos essenciais à pessoa com cegueira, como se vê no Quadro 4. Os resultados indicam que os adolescentes gostam de tocar várias partes do corpo e gostam de ser tocados em partes consideradas mais erotizantes, como pescoço, genitais, seios, nádegas, costas e rosto. $\mathrm{Na}$ adolescência, estas partes surgem como pontos de maior prazer devido à maturação biológica e à produção de hormônios sexuais estimulando a libido. Observa-se, nos resultados, que esta mudança fisiológica é independente do estado de cegueira. Não é raro, todavia, perceberem-se abordagens, por videntes, aos portadores de cegueira, sob o pressuposto de serem estes "pessoas assexuadas", sem vida ou desejos sexuais.

De acordo com Davis (1991), os indivíduos com cegueira são capazes de formar a imagem de uma pessoa ao tocar o rosto da mesma. Poucos videntes têm desenvolvido esta capacidade. Assim, o tato é um dos sentidos mais importantes para os deficientes visuais. A quantidade de informações que podem ser transmitidas por meio do toque, inclusive a leitura, é extraordinariamente imensa e complexa, tornando-se difícil de ser adequadamente avaliada pelos videntes.

A voz, para os que são cegos, revela até mesmo a personalidade. No Quadro 4, o elen- 


\begin{tabular}{|c|c|c|c|c|}
\hline $\begin{array}{l}\text { Questóes pré-formuladas sobre percepção do corpo } \\
\text { com resposta Sim/Não }\end{array}$ & Sim & Não & $\begin{array}{l}\text { Sem } \\
\text { resposta }\end{array}$ & Total \\
\hline Você pensa em seu corpo? & 5 & 1 & -- & 6 \\
\hline Você pensa sobre as partes do seu corpo? & 4 & 2 & -- & 6 \\
\hline Alguma parte de seu corpo o/a preocupa? & 3 & 3 & -- & 6 \\
\hline $\begin{array}{l}\text { Você se preocupa com as mudanças que ocorreram/ocorrem } \\
\text { em seu corpo? }\end{array}$ & 5 & 1 & -- & 6 \\
\hline $\begin{array}{l}\text { Você gostaria que alguém tivesse lhe falado sobre as } \\
\text { mudanças em seu corpo? }\end{array}$ & 2 & 1 & 3 & 6 \\
\hline Você gostaria de ter a aparência diferente da que tem? & 1 & 5 & -- & 6 \\
\hline $\begin{array}{l}\text { Você se importa com o que as pessoas pensam sobre } \\
\text { sua aparência? }\end{array}$ & 3 & 3 & -- & 6 \\
\hline $\begin{array}{l}\text { Você acha que as mudanças em seu corpo podem } \\
\text { interferir no seu relacionamento com as pessoas queridas? }\end{array}$ & 1 & 5 & -- & 6 \\
\hline $\begin{array}{l}\text { Você acha que pode perder alguém querido devido a estas } \\
\text { modificaçóes? }\end{array}$ & 0 & 6 & -- & 6 \\
\hline Você se sente atraente sexualmente? & 6 & 0 & -- & 6 \\
\hline $\begin{array}{l}\text { Você acha que mudou como pessoa depois que seu corpo se } \\
\text { transformou? }\end{array}$ & 4 & 2 & -- & 6 \\
\hline $\begin{array}{l}\text { Você acha que mudou como pessoa depois da primeira menstruação } \\
\text { ou ejaculação? }\end{array}$ & 2 & 3 & -- & 6 \\
\hline
\end{tabular}

Quadro 2 - Distribuição do modo de percepção do próprio corpo por seis adolescentes com cegueira, alunos da Fundação Jonathas Telles de Carvalho, Feira de Santana, Bahia

\begin{tabular}{|l|l|l|l|l|l|l|l|l|l|}
\hline $\begin{array}{l}\text { Quem lhe } \\
\text { falou sobre } \\
\text { as mudanças } \\
\text { em seu corpo? }\end{array}$ & $\mathrm{N}$ & $\begin{array}{l}\text { Qual a parte } \\
\text { do corpo } \\
\text { em que mais } \\
\text { pensa? }\end{array}$ & $\mathrm{N}$ & $\begin{array}{l}\text { De que parte } \\
\text { do corpo } \\
\text { mais gosta? }\end{array}$ & $\mathrm{N}$ & $\begin{array}{l}\text { Qual a parte } \\
\text { que você acha } \\
\text { mais bonita? }\end{array}$ & $\mathrm{N}$ & $\begin{array}{l}\text { Se você tivesse } \\
\text { que mudar algo } \\
\text { no seu corpo } \\
\text { o que mudaria? }\end{array}$ & $\mathrm{N}$ \\
\hline Professor & 1 & Partes íntimas & 1 & Mãos & 1 & Cabeça & 1 & Cabelo & 1 \\
Colegas & 2 & Cabelo & 1 & Pés & 1 & Cabelo & 2 & Mais alto & 1 \\
Irmão & 1 & Todo o corpo & 2 & Pênis & 1 & Pernas & 2 & Menos gordo & 1 \\
Mãe & 3 & Seios & 1 & Cabelo & 2 & Olhos & 1 & Nada & 1 \\
Ninguém & 1 & & & $\begin{array}{l}\text { Pernas } \\
\text { Bigode } \\
\text { Rosto }\end{array}$ & 1 & Mãos & 1 & Seios & 2 \\
& & & & & & Barriga & 1 \\
\hline
\end{tabular}

Quadro 3 - Distribuição das respostas dadas às perguntas sobre sexualidade por seis adolescentes com cegueira, alunos da Fundação Jonathas Telles de Carvalho, Feira de Santana, Bahia*

*Alguns adolescentes deram mais de uma resposta.

co de palavras usadas para traduzir o que a voz revela, leva-nos a admitir que muito do que não pode ser visto com os olhos pode ser percebido através da voz. Aqui também, o aprimoramento da capacidade de extrair informações através da voz excede em muito o que os videntes normalmente contemplam através da voz. 


\begin{tabular}{|l|l|l|l|l|l|}
\hline $\begin{array}{c}\text { Que parte do corpo } \\
\text { você gosta de tocar? }\end{array}$ & N & $\begin{array}{c}\text { Em que parte do corpo } \\
\text { você gosta de ser tocado? }\end{array}$ & N & Que coisa a voz pode revelar? & N \\
\hline Mãos & 2 & Costas & 1 & Bonito & 1 \\
Rosto & 1 & Pescoço & 1 & Feio & 1 \\
Cabelo & 3 & Genitais & 1 & Tristeza & 1 \\
Pernas & 3 & Seios & 1 & Alegria & 1 \\
Braços & 1 & Nádega & 1 & Homem & 1 \\
& Nenhuma & 1 & Mulher & 1 \\
& & Rosto & 1 & Simpático & 2 \\
& & Todo o corpo & 1 & Nada & 1 \\
& & 1 & Amor & 1 \\
& & & & Jeito de ser & 1 \\
& & & Falsidade & 1 \\
& & & Verdadeira & 1 \\
& & & Zangada & 1 \\
& & & Satisfação & 1 \\
& & & Grosseria & 1 \\
& & & &
\end{tabular}

Quadro 4 - Parte do corpo que os seis adolescentes com cegueira, alunos da Fundação Jonathas Telles de Carvalho, Feira de Santana, Bahia, informaram gostar de tocar e de ser tocado, e o que eles, por resposta espontânea, percebem através da voz*

*Alguns adolescentes deram mais de uma resposta.

O Quadro 5 apresenta os resultados dos testes por complementação espontânea de frases. Admite-se que essas complementações revelam o sentimento que os adolescentes nutrem em relação ao seu corpo e como se relacionam com a própria sexualidade. Os resultados permitem concluir que existe, entre os adolescentes cegos entrevistados, uma forma positiva de relacionamento com o próprio corpo, expressa, invariavelmente, de forma positiva, com palavras tais como bonito, muito bonito, lindo e fonte de prazer. Em relação às modificações da puberdade, observa-se uma variação de sentimentos que vai desde normalidade a insatisfação. Estes tipos de comportamento são também característicos da fase da adolescência nos videntes.

Em relação ao corpo do sexo oposto, mesmo para aqueles que ainda não conhecem, existe uma busca por formas de expressar o que imaginam, a exemplo da adolescente $n^{\circ} 1$, de
19 anos, que está namorando pela primeira vez, que disse: "Desconhecido, sei que tenho muito a descobrir. É um mar que pretendo navegar".

Observou-se a falta de informação acerca dos processos naturais da puberdade, como a ejaculação: dos seis adolescentes, somente três responderam alguma coisa, mesmo assim, após uma rápida explicação; os demais preferiram se omitir. Com relação à menstruação, dois dos adolescentes não deram nenhuma resposta.

Ao falarem sobre as manifestaçôes da sexualidade, como o sexo, o ser tocado, o namoro e o casamento, os adolescentes expressaram curiosidade, boa aceitação e, inclusive, o desejo de construir uma família, desejos esses reconhecidamente semelhantes aos da maioria dos jovens videntes. A grande diferença consiste, todavia, na forma como a sociedade encara a sexualidade da pessoa com cegueira, e não na maneira como o deficiente visual vivencia sua sexualidade. 


\begin{tabular}{|c|c|c|c|c|c|c|}
\hline $\begin{array}{l}\text { Frases para } \\
\text { complementação }\end{array}$ & $\mathrm{N}^{\circ} 1$ & $\mathrm{~N}^{\circ} 2$ & $N^{\circ} 3$ & No4 & $\mathrm{N}^{\circ} 5$ & No6 \\
\hline Meu corpo... & $\begin{array}{l}\text { Sentir e dar } \\
\text { prazer }\end{array}$ & Bonito & Bonito & Lindo & $\begin{array}{l}\text { Muito } \\
\text { bonito }\end{array}$ & Bonito \\
\hline Gostaria que... & Família feliz & Mais magro & $\begin{array}{l}\text { Nada } \\
\text { mudasse }\end{array}$ & Amor & $\begin{array}{l}\text { Mais } \\
\text { bonito }\end{array}$ & Enxergasse \\
\hline Me tocar... & Desejo & No rosto & --- & Muito & Todo & --- \\
\hline Gosto de... & Beijar & Jogo & Passear & Tudo & Dormir & Música \\
\hline Minha aparência... & Boa & $\begin{array}{l}\text { Bonita, } \\
\text { simpática }\end{array}$ & Maravilhosa & Simpático & Bonita & Boa \\
\hline A menstruação... & Normal & Não ligo & É ruim & --- & Não gosto & --- \\
\hline A ejaculação... & $\begin{array}{l}\text { Uma } \\
\text { conseqüência }\end{array}$ & --- & --- & Às vezes & --- & Bom \\
\hline Gosto de falar... & Coisas boas & Muito & --- & Muito & $\begin{array}{l}\text { Coisas } \\
\text { bonitas }\end{array}$ & De futebol \\
\hline Os seios crescem... & Ótimo & Ruim & --- & $\begin{array}{l}\text { Coisa que } \\
\text { menos } \\
\text { gosto }\end{array}$ & Ligeiro & --- \\
\hline Os pêlos aparecem... & Normal & Bom & --- & Admiro & Muitos & Sim \\
\hline O corpo masculino... & Desconhecido* & Bom & $\begin{array}{l}\text { Não gosto } \\
\text { muito }\end{array}$ & Simpático & $\begin{array}{l}\text { Muito } \\
\text { bonito }\end{array}$ & Bom \\
\hline O corpo feminino... & Sem mistério & Maravilhoso & $\begin{array}{l}\text { Feio, horrível, } \\
\text { não gosto }\end{array}$ & Bonito & $\begin{array}{l}\text { Muito } \\
\text { bonito }\end{array}$ & Bonito \\
\hline O sexo... & Amor & $\begin{array}{l}\text { Bom, eu } \\
\text { gosto, apesar } \\
\text { de não ter } \\
\text { praticado }\end{array}$ & --- & Amor & Não sei & Bom \\
\hline Namorar... & Bom, ótimo & $\begin{array}{l}\text { Gosto muito, } \\
\text { apesar de } \\
\text { algumas } \\
\text { dificuldades }\end{array}$ & $\begin{array}{l}\text { É bom. } \\
\text { Nunca } \\
\text { experimentei }\end{array}$ & Muito & Nunca & Muito bom \\
\hline O casamento... & $\begin{array}{l}\text { União, } \\
\text { com sexo, } \\
\text { com tudo }\end{array}$ & Bonito e bom & Bom, ótimo & $\begin{array}{l}\text { Casar e ter } \\
\text { filhos }\end{array}$ & $\begin{array}{l}\text { Nunca } \\
\text { também }\end{array}$ & É bom \\
\hline Ser tocado... & $\begin{array}{l}\text { Desperta } \\
\text { alguma coisa. } \\
\text { É bom, } \\
\text { a gente sente } \\
\text { uma coisas } \\
\text { boas }\end{array}$ & No rosto & $\begin{array}{l}\text { Mais ou } \\
\text { menos }\end{array}$ & Gosto & $\begin{array}{l}\text { Por toda } \\
\text { minha } \\
\text { família }\end{array}$ & Bom \\
\hline
\end{tabular}

Quadro 5 - Resultado da complementação de frases feita pelos seis adolescentes com cegueira, alunos da Fundação Jonathas Telles de Carvalho, Feira de Santana, Bahia

*A adolescente complementou: "Sei que tenho muito a descobrir. É um mar que pretendo navegar".

Atenção especial merece o comportamento da adolescente $n^{\circ} 3$, que, no conjunto das frases, deixou de completar seis itens e, nos demais, apresentou negatividade, principalmente em relação ao corpo masculino, como também ao feminino e à menstruação, isto é, àquilo que a confirma mulher. Porém, em sua auto-imagem, ela se qualifica como "maravilhosa" (QUADRO 
3). Esta mesma adolescente, durante o contato pesquisador/pesquisado, comportou-se de forma impaciente e inquieta, afirmando que não era cega, apesar de se locomover de forma igual à dos seus companheiros e de constar na avaliação médica, registrada na ficha escolar, que a mesma é portadora de cegueira congênita. Esta observação corrobora a afirmativa de Gil (2000) de que, na fase da adolescência dos indivíduos com cegueira, alguns manifestam, de forma acentuada, sentimentos de revolta contra a deficiência, por não aceitarem as limitaçôes e a discriminação social. Há grande influência da sociedade no padrão de beleza que o adolescente busca para si, o que pode levar à angústia e à insegurança quando o assunto é o corpo (SUPLICY; EGYPTO, 1995).

A fim de melhor explorar o aspecto da autovaloração nos adolescentes com cegueira, construiu-se um instrumento em arte plástica, que constava de um corte vertical em uma escada, com seis degraus, passível de ser percebida com as mãos, por tato, em alto-relevo. Os adolescentes eram solicitados a indicar, com os dedos, subindo os degraus, em qual altura eles se reconheciam em relação a cada uma das dez palavras ditas pela Pesquisadora. Na Figura 1, apresenta-se o resultado da aplicação desta escala de autovaloração. Nota-se a confirmação da elevada auto-estima entre esses adolescentes com cegueira: eles se percebem como pessoas fortes, inteligentes, alegres, bonitas, amadas e enturmadas. Este resultado é indicativo de bom relacionamento com a própria sexualidade, pois a auto-estima é de fundamental importância para se estabelecer uma vida afetivo-sexual prazerosa. Evidencia-se, assim, que a falta da visão não interfere na percepção positiva sobre si mesmo. A auto-estima permite ao indivíduo crescer emocionalmente, ter segurança, ser alegre, livre, otimista e com capacidade de dar e receber afeto. Concluiu-se que essas qualidades independem de deficiência visual.

Finalmente, o estudo da literatura pertinente e os dados coletados revelaram a inexistência de informações sistemáticas sobre educação sexual para adolescentes com cegueira, o que, além de ser uma violação aos direitos dos nãovidentes, torna mais desafiadora a experiência de vida nesta fase. No sentido de contribuir para o tema, uma das Autoras (FRANÇA, 2002) desenvolveu e testou entre educadores especiais um modelo pedagógico de educação sexual para adolescentes com cegueira, reconhecendo ser este o primeiro modelo proposto no Brasil.

\section{CONCLUSÕES}

O estudo realizado direciona para as seguintes conclusôes:

a) Nos adolescentes com cegueira, a ado-

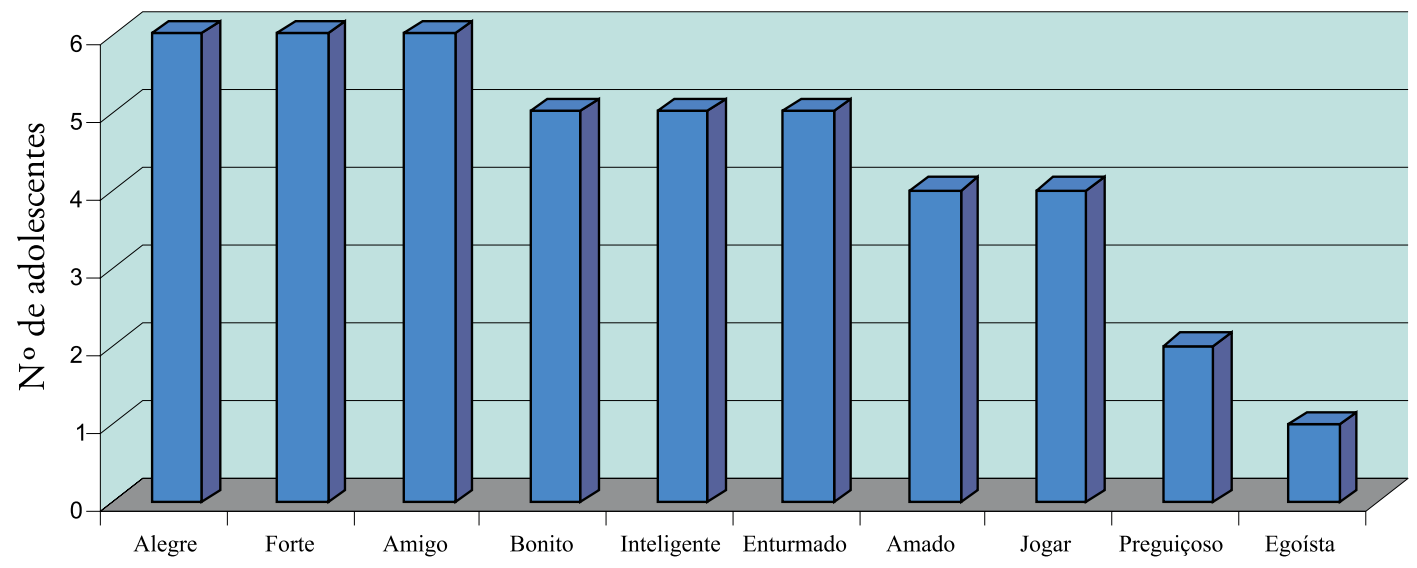

Figura 1 - Resultado da aplicação do teste de autovaloração em seis adolescentes com cegueira, alunos da Fundação Jonathas Telles de Carvalho, Feira de Santana, Bahia 
lescência se caracteriza da mesma forma que nas pessoas dotadas de visão, isto é, com deslumbramentos, inseguranças, desejos e sonhos.

b) Existe notória auto-estima nos adolescentes com cegueira.

c) Não obstante a visão ser o principal meio para construção da imagem corporal, os adolescentes com cegueira conseguem a construçấo dessa imagem através do tato e da audição, principalmente.

d) O toque do próprio corpo e a forma como outras pessoas os descrêem são as fontes fundamentais de informação para a construção da imagem corporal nos adolescentes com cegueira.

e) Não existem modelos pedagógicos especiais orientando adolescentes com cegueira sobre as modificaçóes corporais da puberdade e a sexualidade.

f) É urgente a implantação de programas pedagógicos para orientação sexual dos portadores de cegueira, assim como para desfazer preconceitos em relação à manifestação da sexualidade nessas pessoas.

\title{
Self body image and sexuality in young blind students of a special public school in Feira de Santana, Bahia
}

\begin{abstract}
Six congenital blind adolescents, who attend the Jonathas Telles de Carvalho Foundation, in Feira de Santana, Bahia, Brazil, agreed on participating in this research project, by answering questions on their self corporal image. The results showed that blind adolescents have true perception of their body image that is built up by listening to others and by touching their own bodies. In every blind adolescent interviewed, high self-esteem and self-perception of being sexually attractive were observed. In spite of being poorly informed about body changes in adolescence, the blind students are aware of those alterations. Similar to any young boy or girl who can see, the blind students hope to have a sexual and affectionate relationship with a partner. The lack of special pedagogical models in Brazil to develop their sexual education stresses their adolescence challenges and predispose them to more social prejudice.
\end{abstract}

Keywords: Body image. Sexuality. Blindness. Adolescence.

\section{REFERENCIAS}

DAVIS, P. K. O poder do toque. São Paulo: Best Seller, 1991.

FRANÇA, D. N. O. Imagem corporal e sexualidade em adolescentes com cegueira em escolas públicas de Feira de Santana. 2002. 98f. Dissertação (Mestrado em Educação Especial) - Departamento de Educación, Centro de Referencia Latinoamericano para la Educación Especial, La Habana, 2002. Dissertação defendida na Universidade Estadual de Feira de Santana.
GIL, M. (Org.). Caderno da TV escola: Deficiência visual. Brasília, DF: MEC, Secretaria de Educação à Distância, 2000. p.55-62.

SCHOENFELD, W. A. El cuerpo y la imagen corporal en los adolescentes. In.: CAPLAN, G. (Comp.). El desarrollo del adolescente. Buenos Aires: Paidós, 1968. p.27-41.

SUPLICY, M. ; EGYPTO, A. C. Sexo se aprende na escola. São Paulo: Olho d'Água, 1995. 
TIBA, I. Puberdade e adolescência: desenvolvimento biopsicossocial: esquema corporal. 3. ed. São Paulo: Ágora, 1986.
VIGOTSKY, L. S. Obras completas. La Habana: Pueblo y Educación, 1995. v.5, p.41-48.

\section{Agradecimentos}

Aos entrevistados, por aceitarem colaborar conosco nesta pesquisa, e à Fundação Jonathas Telles de Carvalho, por disponibilizar as informaçôes necessárias para que fosse possível conhecer uma vivência diferente. 